\title{
The impact of thyroid function on intrauterine insemination outcome - a retrospective analysis
}

\author{
Birgit Jatzko ${ }^{1}$, Elisabeth Vytiska-Bistorfer ${ }^{1}$, Alexandra Pawlik', Regina Promberger ${ }^{2}$, Klaus Mayerhofer ${ }^{1}$ \\ and Johannes $\mathrm{Ott}^{1 *}$
}

\begin{abstract}
Background: Hashimoto's thyroiditis is the most common endocrinopathy in premenopausal women, and is associated with various gynecological problems, including recurrent miscarriage and unexplained infertility. A possible influence of Hashimoto's thyroiditis on the success of intrauterine insemination seems likely, but has not been evaluated as yet. Therefore, the aim of our study was to retrospectively analyze the impact on intrauterine insemination outcome of thyroid function and markers suggestive for Hashimoto's thyroiditis.

Methods: Retrospective cohort study in a tertiary care center of 540 women who underwent Intrauterine Insemination. The clinical pregnancy rate was the main outcome parameters. The following possible influencing factors were tested: thyroid-stimulating hormone (TSH); thyroid autoantibodies; age; body mass index; type of sterility (primary/secondary); parity; male factor; presence of PCO syndrome; ovulation induction; ovarian stimulation; and current thyroid medication.
\end{abstract}

Results: The overall clinical pregnancy rate was 6.9\% (37/540). Age, thyroid hormone supplementation for thyroidstimulating hormone (TSH) levels $>2.5 \mathrm{micro}-\mathrm{IU} / \mathrm{ml}$, and ovulation induction with HCG were significantly predictive in the multivariate analysis $(p<0.05)$ as influencing factors for the pregnancy rate after intrauterine insemination.

Conclusions: Women undergoing intrauterine insemination seem to benefit from a strict thyroid hormone supplementation regimen in order to achieve lower TSH levels.

Keywords: Intrauterine insemination, Hypothyroidism, Autoimmune thyroiditis, TSH, Target value

\section{Background}

Intrauterine insemination (IUI) is a simple treatment option for patients with infertility. In detail, a $0.2-0.5 \mathrm{ml}$ processed sperm suspension is deposited with a small catheter transcervically in the uterus, usually without imaging guidance [1]. Clomifene citrate (CC) is often used for ovarian stimulation, and Human Choriogonadotropin (HCG) can be administered intramuscularly to induce ovulation. IUI results in mean pregnancy rates of $10-20 \%$ per patient. However, it can vary individually from $5-70 \%$, depending on the indication, which might often be infertility of unknown origin (unexplained infertility) or slightly poor sperm quality [2].

\footnotetext{
* Correspondence: johannes.ott@meduniwien.ac.at

'Department of Obstetrics and Gynecology, Clinical Department of Gynecologic Endocrinology and Reproductive Medicine, Medical University of Vienna, Waehringer Guertel 18-20, 1090 Vienna, Austria

Full list of author information is available at the end of the article
}

Hashimoto's thyroiditis (HT), a chronic autoimmune thyroiditis, is the most common endocrinopathy in premenopausal women in developed countries, with an incidence of $5-10 \%$, and is the most frequent cause of subclinical hypothyroidism in women in iodine-sufficient areas. Worldwide, iodine deficiency is still the most prevalent cause of thyroid dysfunction [3,4]. Typically, these women show elevated levels of antibodies against thyroperoxidase (TPO-Ab). Various studies have demonstrated that $\mathrm{HT}$ is associated with various gynecological problems. These include recurrent miscarriage [5-12]; otherwise unexplained infertility, defined by the absence of pregnancy after one year of sexual intercourse without contraception [12]; in vitro fertilization failure [13]; and resistance against $\mathrm{CC}$ stimulation in women with polycystic ovary syndrome (PCO-S) [14].

Moreover, the relationship between thyroid dysfunction and negative outcomes for the mother in terms of 
miscarriage, preterm delivery and preeclampsia as well as for child in terms of decreased intelligence quotient and birth weight is relatively well known [15,16]. Even subclinical hypothyroidism without thyroid autoantibodies seems to be associated with the above mentioned problems [16-19]. Treatment of overt hypothyroidism during pregnancy is, therefore, mandatory and consists of levothyroxine therapy adjusted to achieve normal trimester-specific serum levels of thyroid stimulating hormone (TSH). In addition to the fact that recommendations for treatment of subclinical hypothyroidism before and during pregnancy differ among professional organisations, a vigorous debate is ongoing on the pros and cons of universal screening for thyroid disease during pregnancy versus targeted case finding [20].

The influence of HT and thyroid hypofunction on IUI success has never been examined. We, thus, aimed to retrospectively evaluate a possible association between TPO-Ab levels and thyroid function parameters with regard to IUI outcome.

\section{Methods}

In a retrospective cohort study, we included all 540 patients who underwent an IUI at the Clinical Department of Gynecologic Endocrinology and Reproductive Medicine of the Medical University of Vienna, Austria, from January 2008 to December 2011. None of the women revealed any additional severe endocrine diseases including adrenogenital syndrome, Cushing's syndrome and others. Thus, no patients had to be excluded. The study was approved by the Institutional Review Board of the Medical University of Vienna (IRB number: 1751/2012). The indications, the whole proceeding and the assessment for the quality of semen were in accordance with the international guidelines for IUI [1].

\section{Outcome parameters and evaluated predictive factors}

Data were retrieved by retrospective chart review. The primary outcome parameter after IUI was the (clinical) pregnancy rate diagnosed by ultrasound (positive heart rate). The following parameters were analyzed as possible influencing factors on IUI outcome: TSH; TPO-Ab; thyroglobulin antibodies (TG-Ab); patients' age; body mass index (BMI); type of sterility (primary/secondary); parity; male factor; presence of PCO syndrome; metformin treatment for PCO syndrome; ovulation induction with HCG; CC stimulation; and current thyroid medication due to either (i) overt hypothyroidism (defined as $\mathrm{TSH}$ and (total) levothyroxin (T4) $>5.0 \mu \mathrm{IU} / \mathrm{ml}$ and < $64.5 \mathrm{nmol} / \mathrm{l}$, respectively, at any time, or if the woman was under treatment with thyroid hormone supplementation due to overt hypothyroidism as defined above; if women were pre-treated, medical records providing TSH and T4 levels were obtained in order to verify the diagnosis of overt hypothyroidism), or (ii) subclinical hypothyroidism defined as $\mathrm{TSH}>2.5 \mu \mathrm{IU} / \mathrm{ml}$ according to recent guidelines [15]. Notably, all patients who received thyroid hormone supplementation, regardless of whether this was due to overt or subclinical hypothyroidism, revealed a TSH level $<2.5 \mathrm{IU} / \mathrm{mL}$ at the time of insemination.

All serum parameters included in this analysis were obtained on the $3^{\text {rd }}$ to the $5^{\text {th }}$ day of the menstrual cycle with IUI. In our department, the normal range for TSH is $0.44-3.77 \mathrm{mU} / \mathrm{ml}, 0-34 \mathrm{IU} / \mathrm{ml}$ for anti-TPO antibodies, and $0-33 \mathrm{IU} / \mathrm{ml}$ for TG-Ab. These normal ranges had been calculated by the laboratory and all examined serum parameters were determined in the ISO-certified central laboratory of the General Hospital of Vienna, Vienna, Austria using commercially available assays (TSH: REF 11731459, measuring range 0.005-100 $\mu \mathrm{IU} / \mathrm{ml}$, Anti-TG: REF 06368697, measuring range 10.0-4000 IU/ml, AntiTPO: REF 06368590, measuring range 5.0-600 IU/ml, cobas, Roche, Germany).

\section{Statistical analysis}

Nominal variables are reported as numbers and frequencies, and continuous variables as medians and interquartile ranges (IQR). Statistical analysis was accomplished using (i) Wilcoxon-Mann-Whitney-tests for metric variables, (ii) chi-square- or Fisher's exact tests for parametric variables, and (iii) a logistic regression model with Wald's tests to test the statistical significance of all coefficients. Odds ratios (OR) are given, including the 95 per cent confidence interval $(95 \% \mathrm{CI})$. P-values $<0.05$ were considered statistically significant. Statistical analyses were performed with the SPSS software package, version 19 (SPSS, Chicago).

\section{Results}

Detailed patient characteristics are provided in Table 1. There were no cases of hyperthyroidism. The clinical pregnancy rate was $6.9 \%(37 / 540)$. We focused on predictive factors for pregnancy (Table 2). In a univariate analysis, several parameters were found to be associated with a lower chance to achieve a pregnancy after IUI, namely, increasing age, TPO-Ab and TG-Ab levels above the upper level of normal, the need for thyroid medication due to overt hypothyroidism, and the presence of a male factor. In contrast, thyroid hormone supplementation for TSH levels exceeding the threshold of $2.5 \mu \mathrm{IU} / \mathrm{ml}$, and CC stimulation and ovulation induction with HCG were associated with higher pregnancy rates. When these factors were tested in a multivariate analysis, only age (odds ratio 0.94, 95\% CI 0.87-0.99), thyroid hormone supplementation for TSH levels exceeding the threshold of $2.5 \mu \mathrm{IU} / \mathrm{ml}$ (odds ratio 3.31, 95\% CI 1.31-8.35), and ovulation induction with HCG (odds ratio 5.37, 95\% CI 1.72-16.69) remained significantly predictive $(\mathrm{p}<0.05$; Table 2). 
Table 1 Patient characteristics

\begin{tabular}{|c|c|}
\hline Characteristics & \\
\hline$\overline{\text { Age } \text { (years) }^{a}}$ & $34(29-39)$ \\
\hline Body mass index $\left(\mathrm{kg} / \mathrm{m}^{2}\right)^{a}$ & $22.9(20.3-26.0)$ \\
\hline Primary infertility ${ }^{b}$ & $277(51.3)$ \\
\hline Parity $^{b}$ & $0(0-0)$ \\
\hline $\operatorname{TSH}(\mu \mathrm{U} / \mathrm{ml})^{a}$ & $1.6(1.2-2.3)$ \\
\hline$T P O-A b(I U / m /)^{a}$ & $0.0(0-6)$ \\
\hline TPO-Ab > upper level of normal ${ }^{b}$ & $61(11.3)$ \\
\hline$T G-A b(I U / m /)^{a}$ & $0.0(0-22)$ \\
\hline$T G-A b>$ upper level of normal $\left.\right|^{b}$ & $107(19.8)$ \\
\hline Thyroid medication for overt hypothyroidism $b$ & $97(18.0)$ \\
\hline Thyroid medication TSH $>2.5 \mu \mathrm{lU} / \mathrm{m}^{b}$ & $71(13.1)$ \\
\hline Unilateral tubal factor ${ }^{b}$ & $42(7.8)$ \\
\hline Presence of $P C O-S^{C}$ & $89(16.5)$ \\
\hline Metformin treatment ${ }^{b}$ & $34(6.3)$ \\
\hline Clomifen citrate stimulation ${ }^{b}$ & $165(30.6)$ \\
\hline Ovulation induction with $\mathrm{HCG}^{a}$ & $266(49.3)$ \\
\hline Endometrial thickness ${ }^{a}$ & $9.0(8-10)$ \\
\hline Male factor ${ }^{b}$ & $282(52.2)$ \\
\hline
\end{tabular}

Data are provided as ${ }^{\mathrm{a}}$ median (interquartile ranges) or ${ }^{\mathrm{b}}$ number (frequencies).
Based on these results, we chose to compare patients with thyroid medication for TSH levels exceeding the threshold of $2.5 \mu \mathrm{IU} / \mathrm{ml}(\mathrm{n}=71)$ and patients without any thyroid medication $(n=372)$. Patients who received thyroid hormone supplementation for initial TSH levels > $2.5 \mu \mathrm{IU} / \mathrm{ml}$ achieved pregnancy and revealed increased TPO-Ab and TG-Ab levels as well as polycystic ovary syndrome significantly more often (see Table 3 ). In a next step, patients with thyroid medication for TSH levels $>2.5$ $\mu \mathrm{IU} / \mathrm{ml}(\mathrm{n}=71)$ were compared to patients with thyroid medication for overt hypothyroidism ( $\mathrm{n}=97$; Table 3). The latter were significantly older and revealed elevated TPO-Ab levels more often as well as a lower pregnancy rate.

Finally, we compared TSH levels before IUI in women with elevated $(n=61)$ and normal TPO-Ab levels $(n=479$; $1.9 \mu \mathrm{IU} / \mathrm{ml} \mathrm{IQR} 1.2-2.3$ vs. $1.6 \mu \mathrm{IU} / \mathrm{ml}$, IQR $1.1-2.0$, respectively; $\mathrm{p}=0.032)$ and in women with elevated $(\mathrm{n}=107)$ and normal TG-Ab levels $(\mathrm{n}=433 ; 1.5 \mu \mathrm{IU} / \mathrm{ml}$, IQR $1.2-1.9$ vs. $1.5 \mu \mathrm{IU} / \mathrm{ml}$, IQR 1.2-2.0, respectively; $\mathrm{p}=0.845$ ).

\section{Discussion}

The main findings of this retrospective study were the differences between the rates of IUI patients who received thyroid hormone supplementation for TSH levels exceeding the threshold of $2.5 \mu \mathrm{IU} / \mathrm{ml}$ in the pregnancy and the non-pregnancy groups. The rationale was to avoid any kind of subclinical hypothyroidism. The fact

Table 2 Univariate and multivariate analysis

\begin{tabular}{|c|c|c|c|c|c|c|}
\hline & \multirow{2}{*}{$\begin{array}{l}\text { Pregnancy } \\
(\mathrm{N}=37)\end{array}$} & \multirow{2}{*}{$\begin{array}{l}\text { No pregnancy } \\
(\mathrm{N}=503)\end{array}$} & \multicolumn{2}{|c|}{ Univariate analysis } & \multicolumn{2}{|c|}{ Multivariate analysis } \\
\hline & & & OR $(95 \% \mathrm{Cl})^{\mathrm{a}}$ & $p$ & OR $(95 \% \mathrm{Cl})^{\mathrm{a}}$ & $p$ \\
\hline Age (years) ${ }^{b}$ & $30(30-35)$ & $34(29-39)$ & $0.92(0.87 ; 0.98)$ & $0.015^{d}$ & $0.94(0.87 ; 0.99)$ & $0.049^{d}$ \\
\hline Body mass index $\left(\mathrm{kg} / \mathrm{m}^{2}\right)^{b}$ & $20.9(19.9-27.0)$ & $22.9(20.4-26.0)$ & $1.02(0.93 ; 1.07)$ & 0.931 & - & - \\
\hline Primary infertility (vs. secondary infertility) ${ }^{c}$ & $19(51.4)$ & $258(51.3)$ & $1.00(0.95 ; 1.05)$ & 0.861 & - & - \\
\hline Parity ${ }^{6}$ & $0(0-1)$ & $0(0-0)$ & $1.01(0.60 ; 1.71)$ & 0.954 & - & - \\
\hline $\operatorname{TSH}(\mu / U / m /)^{b}$ & $1.6(1.1-2.2)$ & $1.9(1.2-2.4)$ & $0.89(0.46 ; 1.21)$ & 0.556 & - & - \\
\hline TPO-Ab > upper level of normal ${ }^{c}$ & $0(0)$ & $61(12.1)$ & $0.07(0.05 ; 0.10)$ & $0.015^{d}$ & 0 (0;inf) & 0.997 \\
\hline TG-Ab > upper level of normal ${ }^{k}$ & $2(5.4)$ & $105(20.9)$ & $0.22(0.05 ; 0.91)$ & $0.037^{d}$ & $0.87(0.19 ; 4.03)$ & 0.861 \\
\hline Thyroid medication for overt hypothyroidism ${ }^{c}$ & $2(5.4)$ & $95(18.9)$ & $0.25(0.06 ; 1.04)$ & $0.036^{d}$ & $0.54(0.12 ; 2.47)$ & 0.338 \\
\hline Thyroid medication TSH $>2.5 \mu / U / \mathrm{ml}^{\mathrm{F}}$ & $16(43.2)$ & $55(10.9)$ & $6.94(3.60 ; 13.40)$ & $<0.001^{d}$ & $3.31(1.31 ; 8.35)$ & $0.009^{d}$ \\
\hline Presence of PCO-S & $8(21.6)$ & $81(16.1)$ & $0.71(0.31 ; 1.60)$ & 0.407 & - & - \\
\hline Metformin treatment ${ }^{b}$ & $3(8.1)$ & $31(6.2)$ & $1.34(0.31 ; 4.92)$ & 0.500 & - & - \\
\hline Clomifen citrate stimulation $^{c}$ & $19(51.4)$ & $146(29.0)$ & $0.39(0.20 ; 0.77)$ & $0.006^{d}$ & $0.77(0.32 ; 1.85)$ & 0.629 \\
\hline Number of IUI treatment cycle ${ }^{b}$ & $1(1-1)$ & $1(1-1)$ & $0.90(0.59 ; 1.37)$ & 0.638 & - & - \\
\hline Ovulation induction with $\mathrm{HCG}^{c}$ & $27(73.0)$ & $239(47.5)$ & $2.95(1.40 ; 6.22)$ & $0.005^{d}$ & $5.37(1.72 ; 16.69)$ & $0.004^{d}$ \\
\hline Endometrial thickness ${ }^{b}$ & $10(8-11)$ & $8(9-10)$ & $1.09(0.91 ; 1.31)$ & 0.324 & - & - \\
\hline Male factor ${ }^{r}$ & $13(35.1)$ & $269(53.5)$ & $0.47(0.23 ; 0.95)$ & $0.034^{d}$ & $0.60(0.27 ; 1.03)$ & 0.067 \\
\hline
\end{tabular}

${ }^{\mathrm{a}} \mathrm{OR}=$ odds ratio, $95 \% \mathrm{Cl}=95 \%$ confidence interval.

${ }^{\mathrm{b}}$ Continuous variable, provided in median (interquartile range).

${ }^{c}$ Nominal variable, provided in $\mathrm{n}(\%)$.

${ }^{d}$ Italic numbers in $\mathrm{p}$ columns indicate statistical significance. 
Table 3 Comparison of patients with thyroid medication for TSH levels exceeding the threshold of $2.5 \mu \mathrm{IU} / \mathrm{ml}$ and patients without any thyroid medication

\begin{tabular}{|c|c|c|c|c|c|}
\hline & $\begin{array}{l}\text { Thyroid medication } \\
\text { for TSH levels } \\
>2.5 \mu \mathrm{lU} / \mathrm{ml}(\mathrm{n}=71)\end{array}$ & $\begin{array}{l}\text { No thyroid medication } \\
\qquad(\mathrm{n}=372)\end{array}$ & $\begin{array}{l}\text { Thyroid medication for } \\
\text { overt hypothyroidism } \\
\qquad(\mathrm{n}=97)\end{array}$ & $p^{d}$ & $p^{e}$ \\
\hline$\overline{\text { Age } \text { (years) }^{a}}$ & $33(27-40)$ & $33(28-39)$ & $34(30-39)$ & 0.324 & $0.047^{c}$ \\
\hline Body mass index $\left(\mathrm{kg} / \mathrm{m}^{2}\right)^{a}$ & $22.3(19.4-25.1)$ & $22.9(20.3-26.7)$ & $23.1(21.4-25.1)$ & 0.260 & 0.340 \\
\hline Primary infertility (vs. secondary infertility) & $36(50.7)$ & $202(54.3)$ & $39(40.2)$ & 0.578 & 0.176 \\
\hline Parity ${ }^{p}$ & $0(0-1)$ & $0(0-1)$ & $0(0-1)$ & 0.961 & 0.667 \\
\hline$T S H(\mu / U / m /)^{a}$ & $1.6(1.1-2.2)$ & $1.5(1.1-2.0)$ & $1.4(0.4-2.2)$ & 0.422 & 0.107 \\
\hline$T P O-A b>$ upper level of normal ${ }^{b}$ & $8(11.3)$ & $14(3.8)$ & $39(40.2)$ & $0.014^{c}$ & $<0.001^{c}$ \\
\hline TG-Ab > upper level of normal ${ }^{b}$ & $22(31.0)$ & $57(15.3)$ & $28(28.9)$ & $0.004^{c}$ & 0.767 \\
\hline Presence of PCO-S ${ }^{b}$ & $16(22.5)$ & $56(15.1)$ & $17(17.5)$ & $<0.001^{c}$ & 0.419 \\
\hline Metformin treatment ${ }^{b}$ & $5(7.0)$ & $19(5.1)$ & $10(10.3)$ & 0.565 & 0.588 \\
\hline Clomifen citrate stimulation ${ }^{b}$ & $23(32.4)$ & $115(30.9)$ & $27(27.8)$ & 0.805 & 0.523 \\
\hline Number of IUI treatment cycle ${ }^{a}$ & $1(1-1)$ & $1(1-1)$ & $1(1-1)$ & 0.063 & 0.598 \\
\hline Ovulation induction with $\mathrm{HCG}^{b}$ & $36(50.7)$ & $181(48.7)$ & $49(50.5)$ & 0.752 & 0.981 \\
\hline Endometrial thickness ${ }^{a}$ & $9(8-10)$ & $9(8-10)$ & $9(8-10)$ & 0.866 & 0.864 \\
\hline Male factor ${ }^{b}$ & $35(49.3)$ & $195(52.4)$ & $52(53.6)$ & 0.629 & 0.581 \\
\hline Pregnancy rate ${ }^{b}$ & $16(23.9)$ & $19(5.1)$ & $2(2.1)$ & $<0.001^{c}$ & $<0.001^{c}$ \\
\hline
\end{tabular}

Patients with overt hypothyroidism were excluded for this analysis.

${ }^{a}$ Continuous variable, provided in median (interquartile range).

${ }^{b}$ Nominal variable, provided in $\mathrm{n}(\%)$.

${ }^{c}$ Italic letters indicate statistical significance.

${ }^{\mathrm{d} C}$ Comparison of patients with thyroid medication for TSH levels $>2.5 \mu \mathrm{lU} / \mathrm{ml}$ and patients without thyroid medication.

${ }^{\text {e}}$ Comparison of patients with thyroid medication for TSH levels $>2.5 \mu \mathrm{lU} / \mathrm{ml}$ and patients with thyroid medication for overt hypothyroidism.

that these patients were also more likely to become pregnant after IUI when they were compared to patients without any thyroid hormone supplementation (Table 3) is one of the key findings of our study.

Notably, despite the lower pregnancy rate in patients with thyroid hormone supplementation for overt hypothyroidism than in those with supplementation for subclinical hypothyroidism, which can be explained by the lower age in the latter group (Table 3), a patient's need for thyroid medication due to overt hypothyroidism was not a significant influence on IUI outcome in the multivariate model. This is in accordance with a recent study in IVF patients demonstrating that adequate levothyroxine treatment may overcome the detrimental effects of overt hypothyroidism [21]. These results were quite contradictory to a previous report suggesting the opposite [22]. When comparing the reports, it seems evident that in the study by Busnelli et al., thyrotropin serum levels below $2.5 \mu \mathrm{IU} / \mathrm{ml}$ were maintained, in contrast to a higher threshold of $<4.0 \mu \mathrm{IU} / \mathrm{ml}$ in the study by Scoccia et al. These valuable results are supported by our data. Obviously, infertile women undergoing reproductive medicine procedures benefit from a more generous supplementation with levothyroxine, even in absence of overt hypothyroidism. A recent randomized study has demonstrated that levothyroxine treatment improved embryo quality and pregnancy outcome in subclinical hypothyroid women undergoing IVF [23].

One might argue that, in our study, in women who did not suffer from overt hypothyroidism, but who received thyroid supplementation for subclinical hypothyroidism with TSH levels $>2.5 \mu \mathrm{IU} / \mathrm{ml}$, TSH levels might have been suppressed even more than in non-supplemented women. Hypothetically, this mechanism might have contributed to the increased pregnancy rates. However, we did not observe a difference in TSH levels on the $3^{\text {rd }}$ to the $5^{\text {th }}$ day of the menstrual cycle with IUI, neither in the multivariate model (Table 2) nor in the comparison of patients according to the type of thyroid hormone supplementation (for subclinical hypothyroidism/for overt hypothyroidism/ patients without thyroid hormone supplementation; (Table 3). One could argue that thyroid hormone supplementation overcame fluctuations in thyroid hormone levels or other unknown effects that might have been due to HT [24]. This hypothesis is based on the following considerations: patients who were in need for thyroid hormone supplementation due to TSH levels $>2.5 \mu \mathrm{IU} / \mathrm{ml}$ revealed significantly more often increased thyroid autoantibody levels than patients who did not receive thyroid hormones at all (Table 3). This finding confirms the link between $\mathrm{HT}$ and subclinical hypothyroidism in our patient population. HT has been frequently discussed as a factor 
that negatively influences outcomes in infertility treatment $[5,10,12,13]$. However, higher anti-thyroid antibodies indicative of HT were associated with IUI failure after univariate analysis, but did not remain significant after multivariate analysis, in contrast to subclinical hypothyroidism treated with levothyroxine supplementation (Table 2). This suggests that (i) not HT - the most common cause of hypothyroidism in iodine-sufficient areas $[3,4]$ - but rather, hypothyroidism itself is the more important thyroid factor that influences IUI outcome and (ii) thyroid hormone supplementation ameliorates hidden effects of HT on thyroid hormone levels. This is also supported by the fact that we found lower TSH levels in patients with than patients without elevated TPO-Ab despite the fact all women revealed TSH level $<2.5 \mu \mathrm{IU} / \mathrm{ml}$ at the time of IUI. However, it is unlikely that this explains the whole positive influence of thyroid hormone supplementation on pregnancy rates in our study. We find it hard to provide further explanations. It is evident that future studies are warranted to clarify the value of generous levothyroxine supplementation and the threshold that should be used to discriminate between infertile women in need and those not in need of such a treatment. Moreover, the difference between the upper limit of normal provided by the laboratory and the threshold considered to give levothyroxine supplementation in infertile women needs to be emphasized. This suggests that a specific range for women who plan to undergo assisted reproductive procedures could be needed in the future.

In addition to the above mentioned findings and considerations, the comparison of patients without any thyroid medication and patients with thyroid medication for $\mathrm{TSH}>2.5 \mu \mathrm{IU} / \mathrm{ml}$ (Table 3) revealed that the latter achieved pregnancy more often and suffered from PCO$\mathrm{S}$ more often. A previous report has already demonstrated a three-fold higher incidence of autoimmune thyroid diseases in women with PCO-S than in the general female population [25]. However, as demonstrated in Table 2, PCO-S did not independently contribute to the pregnancy rates after IUI.

Notably, ovulation induction with HCG was another factor that was significantly associated with clinical pregnancy after IUI. This is in accordance with previous studies $[26,27]$. After multivariate analysis, the parameter "male factor" differed only by trend $(\mathrm{p}=0.067)$ between patients who achieved a clinical pregnancy and those who did not. This is likely due to the small number of patients in the pregnancy group. The presence of a male factor has frequently been reported as an influencing parameter on IUI outcome [28].

The study must be interpreted within its limitations: (i) its retrospective design; and (ii) the low pregnancy rate, which resulted in a small number of patients in the pregnancy group. In our study, the clinical pregnancy rate after IUI was $6.9 \%$. This is comparatively low compared to the literature, which reports rates of about $10-20 \%[2,29]$. Notably, in our department, many IUI procedures were performed according to the patient's desire. This was the case for couples who could not afford an IVF treatment and opted for IUI, for example, in cases of infertility due to a moderate male factor, and for women aged 40 years or older. The latter is also highlighted by age distribution, as demonstrated in Table 2. Women who did not achieve pregnancy had a median age of 34 years, with an upper IQR level of 39. Moreover, increasing age remained a significant risk factor for IUI failure after multivariate analysis. This is in accordance with previous studies [29-32]. (iii) One of the most common reasons for hypothyroidism is iodine deficiency. Unfortunately, we cannot provide data on iodine status in our patients. However, since the second iodine prophylaxis, Austria is not to be considered a region of iodine deficiency any more. Moreover, all our patients were recommended to use common micronutrient supplementation preparations. These always include at least $100 \mu \mathrm{g}$ iodine per day. Nonetheless, the lack of data on iodine status has to be considered a study limitation.

\section{Conclusions}

Our study provides the following key findings: (i) "classic" predictive factors for IUI outcome, including age, ovulation induction with HCG and - although only differing by trend -the presence of a male factor were confirmed; (ii) women with overt hypothyroidism who received thyroid hormone supplementation that was sufficient to keep TSH levels $<2.5 \mu \mathrm{IU} / \mathrm{ml}$ were not at greater risk of IUI failure; and (iii) for women who received thyroid hormone supplementation due to subclinical hypothyroidism, with TSH levels $>2.5 \mu \mathrm{IU} / \mathrm{ml}$, higher pregnancy rates were found after IUI. These findings suggest that women undergoing IUI, and, hypothetically, also other medical interventions for infertility, benefit from a strict thyroid hormone supplementation in order to achieve lower TSH levels. Although our study sheds new light on the issue of the influence of thyroid function and thyroid supplementation on IUI success, prospective studies are needed to confirm our results. Future work should also clarify whether the TSH threshold for thyroid hormone supplementation should be decreased for infertile women.

\section{Competing interests}

All authors declare that there are no potential conflicts of interest, whether of a financial or other nature.

\section{Authors' contributions}

All authors contributed to the writing process of the manuscript and approved the final version. $\mathrm{BJ}$ and $\mathrm{JO}$ were the principal investigators, wrote the study protocol and manuscript. AP, EV, KM and RP worked as co-investigators performed the literature search and were crucially involved in data interpretation. All authors read and approved the final manuscript. 


\section{Author details}

1 Department of Obstetrics and Gynecology, Clinical Department of Gynecologic Endocrinology and Reproductive Medicine, Medical University of Vienna, Waehringer Guertel 18-20, 1090 Vienna, Austria. ${ }^{2}$ Department of Surgery, Medical University of Vienna, Waehringer Guertel 18-20, 1090 Vienna, Austria.

Received: 4 February 2014 Accepted: 31 March 2014

Published: 5 April 2014

\section{References}

1. The ESHRE Capri Workshop Group: Intrauterine insemination. Hum Reprod Update 2009, 15:265-277.

2. Abdelkader AM, Yeh J: The potential use of intrauterine insemination as a basic option for infertility: a review for technology-limited medical settings. Obstet Gynecol Int 2009, 2009:584837.

3. Hayashi N, Tamaki N, Konishi J, Yonekura Y, Senda M, Kasagi K: Sonography of Hashimoto's thyroiditis. J Clin Ultrasound 1986, 14:123-126.

4. Peterson CM: Thyroid disease and fertility. Immunol Allerg Clin North Am 1994, 14:725-738.

5. Poppe K, Velkeniers B, Glinoer D: Thyroid disease and female reproduction. Clin Endocrinol (Oxf) 2007, 66:309-321.

6. Stagnaro Green A, Roman SH, Cobin RH, El Harazy E, Alvarez Marfany M, Davies TF: Detection of at-risk pregnancy by means of highly sensitive assays for thyroid autoantibodies. JAMA 1990, 19:1422-1425.

7. Lejeune B, Grun JP, de Nayer P, Servais G, Glinoer D: Antithyroid antibodies underlying thyroid abnormalities and miscarriage or pregnancy induced hypertension. Br J Obstet Gynaecol 1993, 100:669-672.

8. Pratt DE, Kaberlein G, Dudkiewicz A, Karande V, Gleicher N: The association of antithyroid antibodies in euthyroid nonpregnant women with recurrent first trimester abortions in the next pregnancy. Fertil Steril 1993, 60:1001-1005

9. Esplin MS, Branch DW, Silver R, Stagnaro-Green A: Thyroid autoantibodies are not associated with recurrent pregnancy loss. Am J Obstet Gynecol 1988, 179:1583-1586.

10. Bussen S, Steck T, Dietl J: Increased prevalence of thyroid antibodies in euthyroid women with a history of recurrent in-vitro fertilization failure. Human Reprod 2000, 15:545-548.

11. Dendrinos S, Papasteriades C, Tarassi K, Christodoulakos G, Prasinos G Creatsas $\mathrm{G}$ : Thyroid autoimmunity in patients with recurrent spontaneous miscarriages. Gynecol Endocrinol 2000, 14:270-274.

12. Van den Boogaard E, Vissenberg R, Land JA, van Wely M, van der Post JA, Goddijn M: Significance of (sub)clinical thyroid dysfunction and thyroid autoimmunity before conception and in early pregnancy: a systematic review. Hum Reprod Update 2011, 17:605-619.

13. Geva E, Vardinon N, Lessing JB, Lerner-Geva L, Azem F, Yovel I: Organspecific autoantibodies are possible markers for reproductive failure: a prospective study in an in-vitro fertilization-embryo transfer programme. Hum Reprod 1996, 11:1627-1631.

14. Ott J, Aust S, Kurz C, Nouri K, Wirth S, Huber JC: Elevated antithyroid peroxidase antibodies indicating Hashimoto's thyroiditis are associated with the treatment response in infertile women with polycystic ovary syndrome. Fertil Steril 2011, 94:2895-2897.

15. De Groot L1, Abalovich M, Alexander EK, Amino N, Barbour L, Cobin RH, Eastman CJ, Lazarus JH, Luton D, Mandel SJ, Mestman J, Rovet J, Sullivan S: Management of thyroid dysfunction during pregnancy and postpartum: an Endocrine Society clinical practice guideline. J Clin Endocrinol Metab 2012, 97:2543-2565

16. Benhadi N, Wiersinga WM, Reitsma JB, Vrijkotte TG, Bonsel GJ: Higher maternal TSH levels in pregnancy are associated with increased risk for miscarriage, fetal or neonatal death. Eur J Endocrinol 2009, 160:985-991.

17. Casey BM, Dashe JS, Wells CE, Mclntire DD, Byrd W, Leveno KJ, Cunningham FG: Subclinical hypothyroidism and pregnancy outcomes. Obstet Gynecol 2005, 105:239-245

18. Haddow JE, Palomaki GE, Allan WC, Williams JR, Knight GJ, Gagnon J, O'Heir CE, Mitchell ML, Hermos RJ, Waisbren SE, Faix JD, Klein RZ: Maternal thyroid deficiency during pregnancy and subsequent neurophysiological development of the child. N Engl J Med 1999, 341:549-555.

19. Negro R, Schwartz A, Gismondi R, Tinelli A, Mangieri T, Stangaro-Green A: Increased pregnancy loss rate in thyroid antibody negative women with
TSH Levels between 2.5 and 5.0 in the first trimester of pregnancy. $J$ Clin Endocrinol Metab 2010, 95:E44-E48.

20. Vila L, Velasco I, González S, Morales F, Sánchez E, Torrejón S, Soldevila B, Stagnaro-Green A, Puig-Domingo M: Controversies in endocrinology: on the need for universal thyroid screening in pregnant women. Eur J Endocrinol 2013, 170:R17-R30.

21. Busnelli A, Somigliana E, Benaglia L, Leonardi M, Ragni G, Fedele L: In vitro fertilization outcomes in treated hypothyroidism. Thyroid 2013, 23:1319-1325

22. Scoccia B, Demir H, Kang Y, Fierro MA, Winston NJ: In vitro fertilization pregnancy rates in levothyroxine-treated women with hypothyroidism compared to women without thyroid dysfunction disorders. Thyroid 2012, 22:631-636

23. Kim CH, Ahn JW, Kang SP, Kim SH, Chae HD, Kang BM: Effect of levothyroxine treatment on in vitro fertilization and pregnancy outcome in infertile women with subclinical hypothyroidism undergoing in vitro fertilization/intracytoplasmic sperm injection. Fertil Steril 2011, 95:1650-1654

24. Ott J, Promberger R, Kober F, Neuhold N, Tea M, Huber JC, Hermann M: Hashimoto's thyroiditis affects symptom load and quality of life unrelated to hypothyroidism: a prospective case-control study in women undergoing thyroidectomy for benign goiter. Thyroid 2011, 21:161-167.

25. Janssen OE, Mehlmauer N, Hahn S, Offner AH, Gärtner R: High prevalence of autoimmune thyroiditis in patients with polycystic ovary syndrome. Eur J Endocrinol 2004, 150:363-369.

26. Gomez R, Schorsch M, Steetskamp J, Hahn T, Heidner K, Seufert R: The effect of ovarian stimulation on the outcome of intrauterine insemination. Arch Obstet Gynecol 2014, 289:181-185.

27. Mitwally MF, Abdel-Razeq S, Casper RF: Human chorionic gonadotropin administration is associated with high pregnancy rates during ovarian stimulation and timed intercourse or intrauterine insemination. Reprod Biol Endocrinol 2004, 7:55.

28. Bensdorp AJ, Cohlen BJ, Heineman MJ, Vandekerckhove P: Intra-uterine insemination for male subfertility. Cochrane Database Syst Rev 2007, 17:CD000360.

29. Jeon YE, Jung JA, Kim HY, Seo SK, Cho S, Choi YS: Predictive factors for pregnancy during the first four intrauterine insemination cycles using gonadotropin. Gynecol Endocrinol 2013, 29:834-838.

30. Wiser A, Shalom-Paz E, Reinblatt SL, Son WY, Das M, Tulandi T: Ovarian stimulation and intrauterine insemination in women aged 40 years or more. Reprod Biomed Online 2012, 24:170-173.

31. Armstrong $S, A$ kande $V$ : What is the best treatment option for infertile women aged 40 and over? J Assist Reprod Genet 2013, 30:667-671.

32. Kamath MS, Bhave P, Aleyamma T, Nair R, Chandy A, Mangalaraj AM: Predictive factors for pregnancy after intrauterine insemination: a prospective study of factors affecting outcome. J Hum Reprod Sci 2010, 3:129-134.

doi:10.1186/1477-7827-12-28

Cite this article as: Jatzko et al:: The impact of thyroid function on intrauterine insemination outcome - a retrospective analysis. Reproductive Biology and Endocrinology 2014 12:28

\section{Submit your next manuscript to BioMed Central and take full advantage of:}

- Convenient online submission

- Thorough peer review

- No space constraints or color figure charges

- Immediate publication on acceptance

- Inclusion in PubMed, CAS, Scopus and Google Scholar

- Research which is freely available for redistribution 